\title{
The Enthusiast's Eye: The Value of Unsanctioned Knowledge in Design Historical Scholarship
}

Paul Hazell and Kjetil Fallan

\section{Introduction}

Drivers of the utility Land Rover (known as the 'Defender' since 1990) often wave at each other when they pass. This is unusual in modern motoring and there is a protocol of course; drivers of Defenders owned by the Army, farmers or the electricity board etc. rarely acknowledge each other. However private individual owners of the Land Rover Defender usually wave. Why? Is it because the first group (soldiers, farmers and contractors) see the Land Rover as purely workhorse, a tool to get the job done? The second group differ, as they have been motivated in some way to spend their own money to buy a capable but rather thirsty, noisy and slow vehicle. Nevertheless, they seem to be saying with a simple wave to a fellow Land Rover owner 'I get it too' (Crathorne, 2012). There is, it seems, a desire to acknowledge their enthusiasm with likeminded strangers (Figure 1).

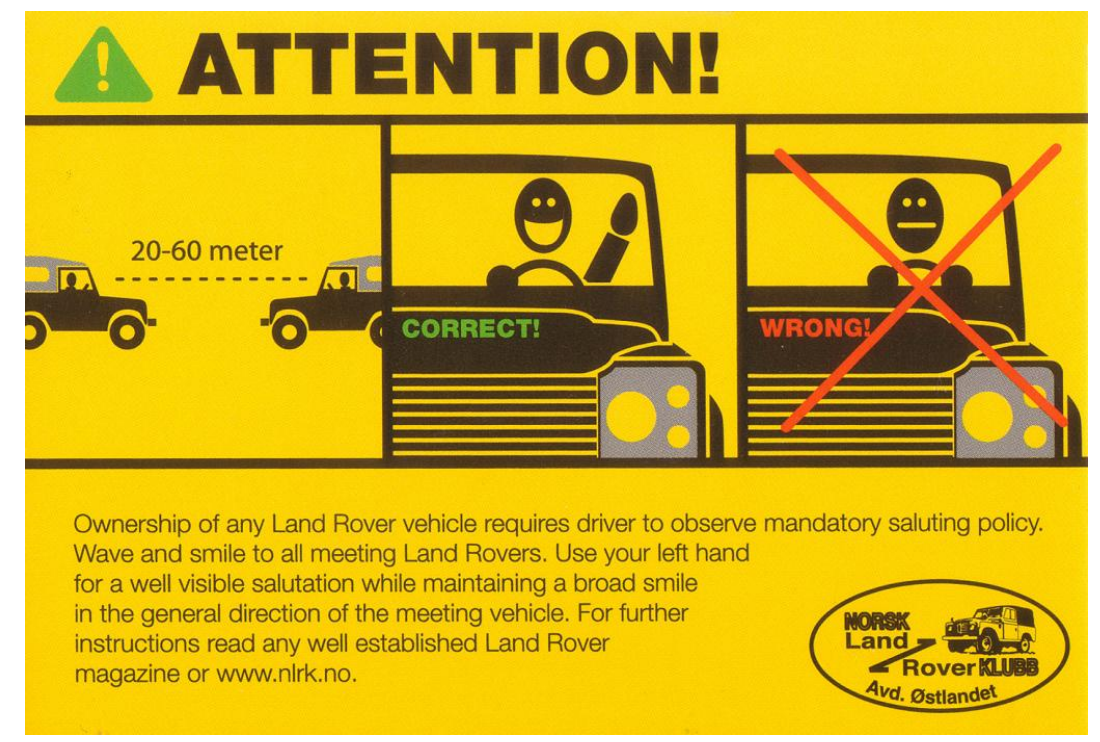

Figure 1: Land Rover Etiquette: Spoof instructional sticker produced by the Norsk Land Rover-klubb. Author's collection. 
Membership of this community also often entails substantial knowledge, both artefactual and contextual, of the shared object of affection (Sudjic, 2008). Such observable manifestations of enthusiasm are highly revealing of the significance of subjective engagement, emotional attachment and 'unsanctioned' knowledge in design culture, and should therefore warrant the attention of design historians.

Much of our reaction to design as users and consumers is subjective. This ranges from the active disliking of particular designs ('this chair is uncomfortable', 'that's an ugly car'), through invisibility ('did you notice the cutlery you used to eat your dinner last night?'), to vague preferences ('I prefer the green one') and onto dedicated enthusiasm for particular artefacts ('The Spitfire is an iconic aircraft') (Author, 2013c). A network of interests exists in relation to the interpretation of materiality starting with the designers themselves through to users, and at times design historians and other academics. These groups exhibit differently nuanced behaviour in relation to their engagement in design, its implementation, consumption and history.

Those in design practice are often extremely enthusiastic about what they do. There is a strong sense amongst graphic designers, for example, that if they are not excited about their latest design they are not doing their job properly (Author, 2014). The level of enthusiasm the resulting designs instil in their users, on the other hand, varies greatly. At times people interact with things without realising they have done so; other times design awareness is more conscious, ranging from dislike or annoyance to satisfaction or pleasure (Norman, 1998; 2004; Keyte, 2013). Occasionally however, these same users will become aware of an artefact as something which triggers or represents experiences or emotions. This can manifest itself as an affection or appreciation of a particular piece of design through to what 
might be described as 'full-blown enthusiasm' or perhaps even as 'object fetishism' (Oddy, 2013).

Designers and users, then, seem both able and willing to accept enthusiasm into their understanding of material culture. Design historians, on the other hand, are much more reluctant to do so as it appears counter to the scholarly traditions of striving for an objective view. Although the historicist mantra of describing the past 'wie es eigentlich gewesen' (as it actually was) is long discarded as an elusive utopian ambition, the academic world's quest for credibility has cast a spell of suspicion on everything subjective. Not only might this push the understanding of enthusiasm as a category of consumer behaviour into the background of design historical scholarship; it also conceals the fact that most design historians are enthusiasts themselves. What we choose to study, and how we go about that task, is - to varying degrees, of course — guided by our subjective preferences, responses and experiences, at times amounting to full-blown enthusiasm for our subject matter and object of study.

Enthusiasm is defined as being passionate about something, making it only a small step to the original sense of the amateur as a lover of something. This etymological excursion might go a long way in explaining why there has been so little enthusiasm for enthusiasm in academic design history: being an enthusiast is dangerously close to being an amateur (in the more pejorative, contemporary meaning of the word). For a discipline still having to legitimise its status as professional practice (Author, 2013a), the fear of being associated with amateurism is quite understandable. The realm of love and passion is intimately linked to the personal, to the private, thus fortifying the dichotomy between the objective and the subjective, between the professional and the amateur/enthusiast. 
However, design historians' fear of amateurism and enthusiasm in their own historical practice seems to be stronger than when they are studying the practice of design itself. There has in recent research in design history been a significant interest in the role of amateur knowledge and skills in the sphere of design practice (Atkinson, 2006; Beegan et al., 2008; Jackson, 2010; Shove et al., 2007), yet no work has been conducted on the role of amateur knowledge in the sphere of design history. This article seeks to address this lacuna, arguing for a more self-reflexive understanding of 'unsanctioned' forms of historical knowledge and their potential contribution to the writing of academic design history.

\section{Unsanctioned Knowledge}

As part of his critical examinations of society's power structures, Michel Foucault introduced the concept 'subjugated knowledges' as a means to acknowledge and mine the riches of those kinds of experiences and expertise that have been suppressed and ignored by the authorities and by authorized accounts: 'by subjugated knowledges one should understand ... a whole set of knowledges that have been disqualified as inadequate to their task or insufficiently elaborated: naive knowledges, located low down on the hierarchy, beneath the required level of cognition or scientificity.' Arguing that this realm of experience and expertise has significant critical potential, Foucault elaborates on what he describes as 'low-ranking knowledges, ... unqualified, even directly disqualified knowledges ... which involve what I would call a popular knowledge (le savoir des gens) though it is far from being a general commonsense knowledge, but is on the contrary a particular, local, regional knowledge, a differential knowledge incapable of unanimity' (Foucault, 1980: 82). 
As in Foucault's examples, drawn from his classic histories of madness, sexuality and punishment, the kind of knowledge we have identified in the enthusiast's eye is 'popular', non-academic, unauthoratative, particular and dispersed. However, describing it as 'subjugated' would be an exaggeration. Therefore, we propose the related, but moderated term 'unsanctioned knowledge'.

Significantly, Foucault makes a case for combining subjugated knowledge with erudite knowledge as a key component in a methodology for exploring a more multivocal and polyvalent past. In fact, it is the very union of these two realms of knowledge that he terms genealogy (Foucault, 1980: 83). Because this latter term is notoriously difficult to define in a satisfactory manner, and because the overall mode of historical inquiry associated with it is controversial, we will not adopt it wholesale. However, we do believe that its basic tenet that combining sanctioned with unsanctioned knowledge will lead to improved historical understanding is well worth carrying forward.

\section{Historian Enthusiasts and Enthusiast Historians}

There are (at least) four ways the enthusiast's eye meets design history: 1) occasionally, the enthusiast is also a professional historian-or vice versa. 2) More commonly, though, is it for the enthusiast to become an amateur historian of their object or field of interest. 3) A related, but more 'open' setting is where the enthusiast collects/organises source material (objects and/or textual/visual material) for use by professional historians. 4) Finally, as a variety of the former category, the enthusiast can act as informant for professional historians.

When the enthusiast and the professional historian are one and the same, a merger of the sanctioned knowledge of academic scholarship and the unsanctioned 
knowledge of enthusiast practices is neatly facilitated. To explore a specific example, when researching the early history of the Land Rover (an example of material culture with a sizable and enthusiastic following) it is of course the enthusiast movement that has lead the way in uncovering the minutiae of the very earliest vehicles built from April 1948. This minutia may seem initially to be only of interest to the dedicated enthusiast, however if the enthusiast is also a design historian such detail can be easily identified and its significance assessed in relation to other evidence applied to boarder themes, in this case with regard to how legends build up around some artefacts. For instance, a key phrase that repeatedly appears with regard to early Land Rover models is that they were regarded as stopgap products by the manufacturer, i.e. temporary and short-lived. Sixty-five years later this shift from stopgap to automotive icon can been seen as an heroic struggle befitting of this dependable and plucky British vehicle (Robson, 1976). However this popularly accepted 'fact' about the vehicle seemed to contradict contemporary Rover company minutes, which discuss large-scale interest in the vehicle before it had reached production in 1948. Further evidence was required. Painstaking research by a member of the Land Rover Series 1 Club using the original engineering drawings held in the company archive revealed that the bulkhead between the cab and engine (a structural component in the Land Rover) soon moved away from a fabricated construction to a pressed steel design requiring a large and expensive press tool (Bishop, 2011). This speeded the means of construction but would only payback over the longer term - the antithesis of what would be done for a temporary stopgap. This apparently tiny detail may only be one small example of how the enthusiast's specific research can help that of the design historian when reaching broader conclusions. But such details can be missed if the 
historian is not engaging with enthusiasts whether as an 'outsider' or as enthusiast him or herself.

As we have seen above, some enthusiasts —often in the capacity of collectors - produce literature on the subject of their enthusiasm. Such accounts can be voluminous, and painstakingly detailed - and accuracy is a prime virtue. Although much of this work would not meet the standards and conventions of academic literature-e.g. because it is normally little concerned with empirical contextualization or with theoretical positions and methodological concerns - it can nevertheless have great scholarly value. This is especially the case when researching the history of objects and object-types outside the canons and conventions of design history, where both secondary literature and documentary evidence may be scarce (Author, 2012).

The lack of engagement with literature from 'the other camp' is mutual, though. Collector-enthusiasts rarely engage in texts written for an academic audience, for obvious reasons: 'Collectors are mainly collecting as a form of escapism, the last thing they want to do in their free time is read heavyweight theoretical discourse about the meta-context of what they collect, in the main they want to acquire more and "better" objects and use literature that facilitates this process' (Oddy, 2013). Furthermore, an academic discussing an artefact is unlikely to be legitimised amongst enthusiasts as they rarely have direct experience of the object they are analysing. Looking at Wiebe Bijker's influential study of the development of the rear driven bicycle as an exception to the collector historians' general disinterest in academic literature (Bijker, 1997), Nicholas Oddy explored this issue further: 
Its reception was negative, principally because Bijker had made the heinous mistake (to collector historians at least) of being factually inaccurate in his history of the machines themselves ..., thus discrediting the rest of the content, no matter how impressive its theorising was. Rather ironically, Bijker had become a victim of the linear, technologically led histories he set out to question (Oddy, 2013).

This is not an argument for design historians to necessarily become enthusiasts for the artefacts being studied however; the default criticism of subjectivity in historical scholarship could be wheeled out against such a position. The interesting point in this case is rather the at times impressive rigidity of the unsanctioned knowledge produced by enthusiasts. In addition there is a lesson to be learned about the perils of making assumptions about e.g. details of an object's construction — perils which can be avoided with improved personal experience with it (Meikle, 1998). So, if not fullblown enthusiasts, design historians can still benefit significantly from subjective experience, further buttressed by appropriate attention to the knowledge produced by collector historians and other enthusiasts.

\section{Enthusiasts as Curators and Informants}

Although written accounts represent a significant form of unsanctioned knowledge, other forms of information are even more prevalent amongst enthusiasts, particularly artefactual and oral sources. Through their active and personal engagement with historical artefacts, enthusiasts become custodians of history. Their activities are sometimes so organised as to aspire to sanctioned forms of knowledge, as when 
enthusiast associations set up and run museums that, at least to the casual visitor, may be hard to distinguish from conventional professional museums. (Figure 3)

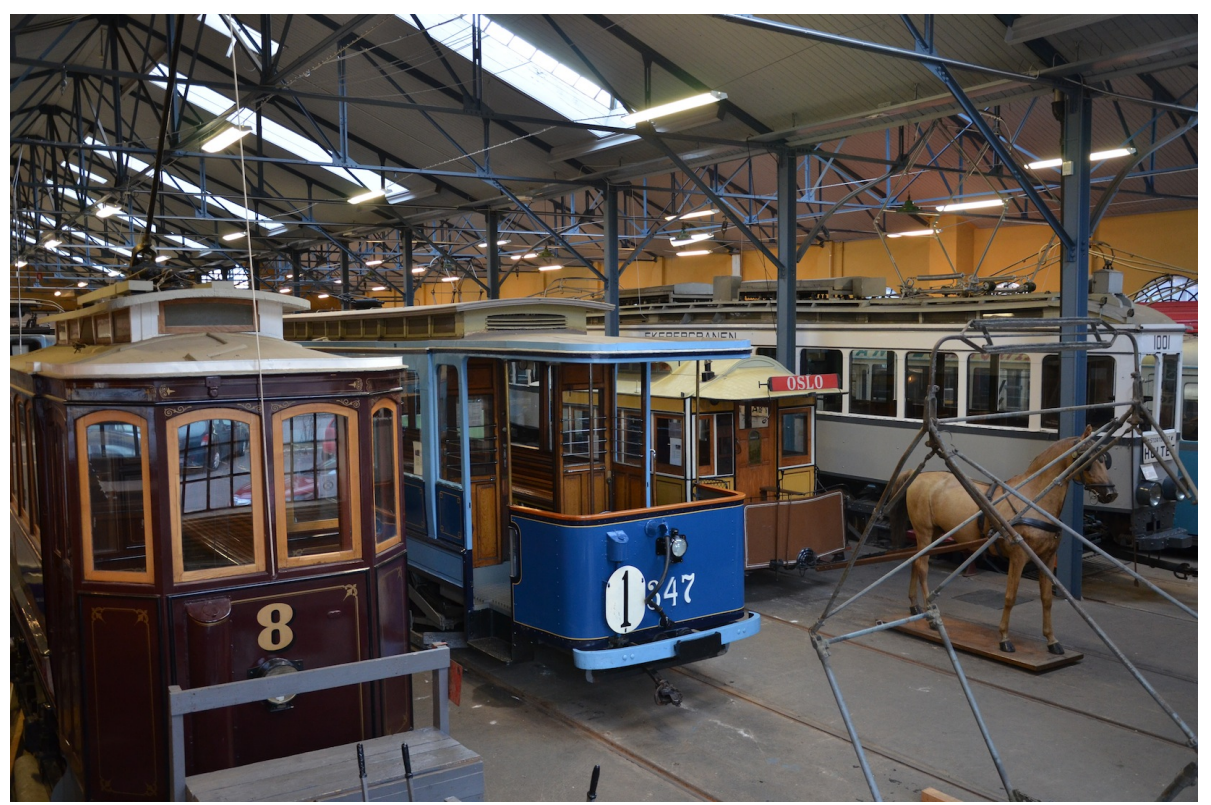

Figure 2: From the exhibition hall at the Oslo Tramway Museum, an institution run entirely by enthusiasts. Photo: Author.

Enthusiasts thus take on the roles of curators, conservationists and archivists. The collections and archives held in such institutions can be as valuable to professional historians as those held in their official sister institutions; even more so at times, as these enthusiasts' museums are normally more specialized and dedicated to material only sparsely represented in professional museums (Author, 2012; Morris, 2013). Occasionally, the two spheres meet, as when private collectors donate their collections to professional museums - a situation that may highlight discrepancies between the unsanctioned knowledge and values of the enthusiast collector and the sanctioned knowledge and professional ethos of the historian curator.

Without going to the extremes of establishing a museum, most enthusiasts and collectors are still eager to share their knowledge and materials, and do so in various 
ways. Many participate in fairs, meetings and other events. Some are more than happy to open up their homes and workshops to likeminded people, be they amateurs or professional historians. (Figure 4)

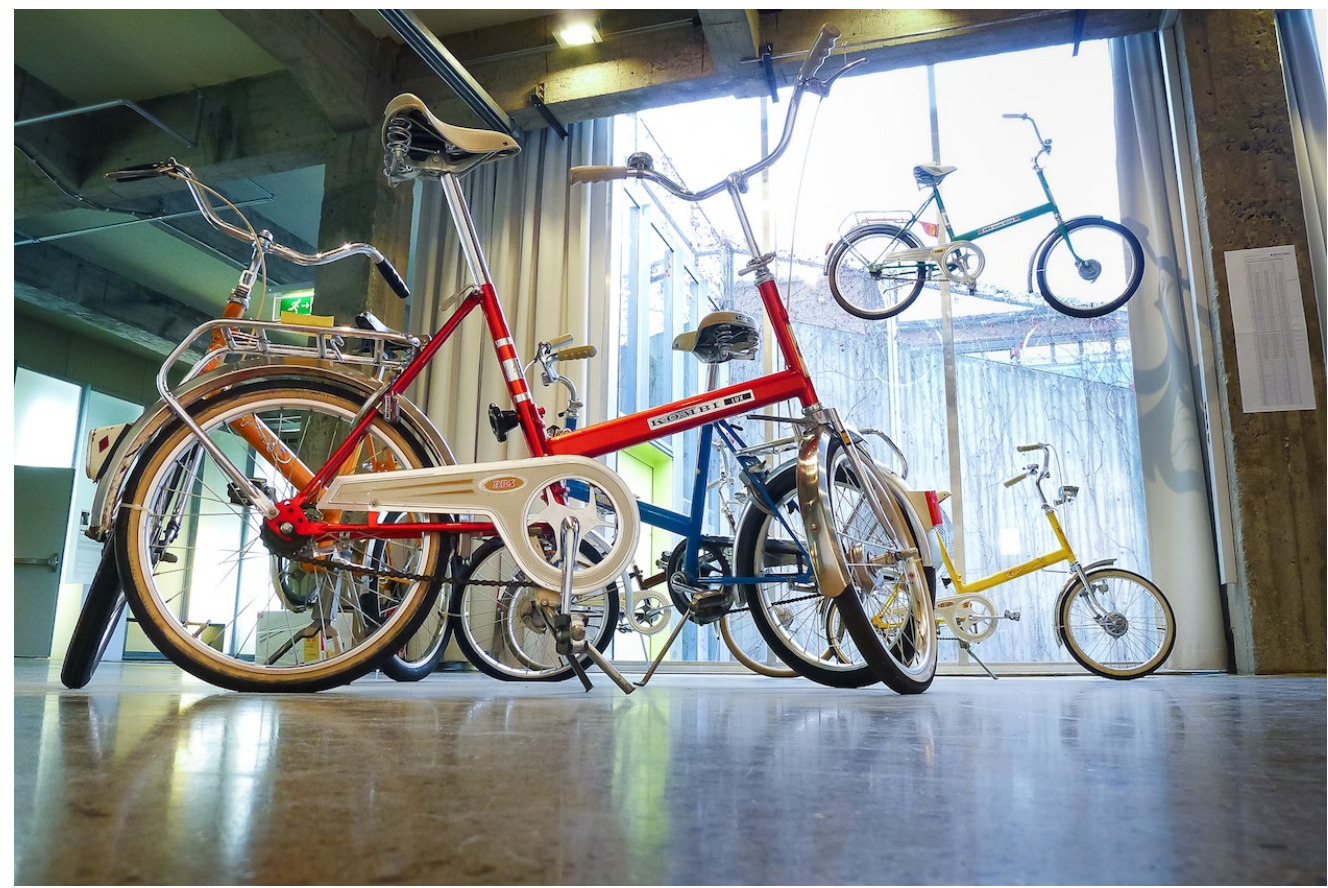

Figure 3: Art historian and enthusiast Hans-Henrik Egede-Nissen curated an exhibition on the DBS Kombi mini-bicycle at the Oslo School of Architecture and Design in 2011. The exhibited bicycles came from the comprehensive collection of the collector, enthusiast, amateur historian and bicycle repairman Einar Bowitz. Photo: Geir A. Rybakken Ørslien.

In recent years online discussion forums and social media have become invaluable sources of enthusiast knowledge - tracking down the exact production year of a specific bicycle took about five minutes with the help of an enthusiast Facebook group (Author, 2013b).

Enthusiast collectors may also be considered de facto curators of design history, further complicating the relations between the professional and the amateur, between the sanctioned and the unsanctioned. Combining personal enthusiasm and business acumen with a sense of cultural heritage work, the entrepreneurs behind the Oslo retro coffee and cocktail bar-cum-vintage design store Fuglen ('The Bird') 
recently teamed up with Norway's premier auction house, Blomqvist, to set up the sales exhibition Norwegian Icons: Important Norwegian Design from the Era 19401975. This commercial context makes the event distinctly different from a similar exhibition organised by a conventional museum, for instance. Nevertheless, with a stated ambition of 'rais[ing] international awareness of Norway's significant contribution to the Scandinavian Mid-Century period, alongside that of Denmark, Sweden and Finland' (Linder, 2013: 15), the initiative was warmly welcomed by the governmentally funded institution charged with the promotion of Norwegian design, the Norwegian Centre for Design and Architecture, and subsequently shown in Tokyo and New York.

Whereas the above example goes a long way in moving enthusiast knowledge into the official, public discourse of design history, collectors can take on the role of curators also in more modest, private settings. In her research on the role of collecting 'kiwiana' in the cultivation of New Zealand national identity, Claudia Bell interviewed collectors of Crown Lynn ceramics. These mundane products are considered iconic of the nation's industrial heritage and relics of a recent past when New Zealand had a relatively self-sufficient consumer goods industry, and Bell argues that the widespread collecting of these artefacts is an attempt at preserving this legacy: 'Each of these collectors truly saw themselves as actively contributing to the preservation of the material history of a nation. Their own "subjective sentiments" harmonized strongly with received collective memories' (Bell, 2013: 56). These enthusiasts can thus be considered as curators of design history, effectively moving this otherwise official, public and professional capacity into the sphere of the personal, particular, popular and nostalgic. 
Beyond their role as curators, enthusiasts also make highly valuable informants because of the disproportionately large and detailed information they possess on the given topic. Of course, this very enthusiasm is also a challenge to the historian in methodological terms, as it may make them particularly prone to promoting a specific version of the events - but this problem is by no means restricted to enthusiasts (Sandino and Partington, 2013). In interviews with enthusiasts for instance there is the ever present danger they will 'spin-off' at a tangent from the question asked as they revel in the opportunity to not only discus the object of their affection, but also demonstrate their depth of knowledge which has now apparently been legitimised by interest from an historian. However this can at times reveal aspects of the story that might otherwise go unnoticed, therefore the historian needs to consider carefully when to let the enthusiast expand and when to rein them in.

Even if one's informants are not full-blown enthusiasts in the most dedicated form, a certain level of enthusiasm for the topic at hand-both from the interviewer and the interviewee-is often indispensable when conducting oral history. Siv Ringdal's ethnological study of how non-permanent work migration from a small Norwegian rural town and New York during the better part of the twentieth century created an exotic enclave of 'Americana astray' relied heavily on her ample personal experience with this phenomenon from her upbringing and family, and would hardly be possible without the widespread pride, nostalgia and enthusiasm for this heritage throughout the local community (Ringdal, 2014). This enthusiasm for the topic, and by extension the likely detailed knowledge of it by the historian themselves, can greatly improve communication with the amateur enthusiast as trust is developed as the interviewee accepts the historian as having 'real' knowledge of the artefact or event in question. This can lead to aspects of the story that might otherwise go 
unnoticed, being identified and woven in as the historian considers both the macro and the micro.

\section{The Enthusiast's Eye: A Multifocal Lens}

It should be clear now, then, that individuals and enthusiast groups dedicated to particular aspects of material culture frequently emerge and manifest themselves in a variety of ways; whether it be clubs, individuals collecting particular items they take an interest in, or re-enactors interacting with objects from the past. These interested groups or individuals can hold considerable knowledge and expertise about an artefact and its history - the most characteristic of which is probably what Oddy calls '[the] experiential knowledge of collecting and its methodologies acquired through ownership of the things' (Oddy, 2013).

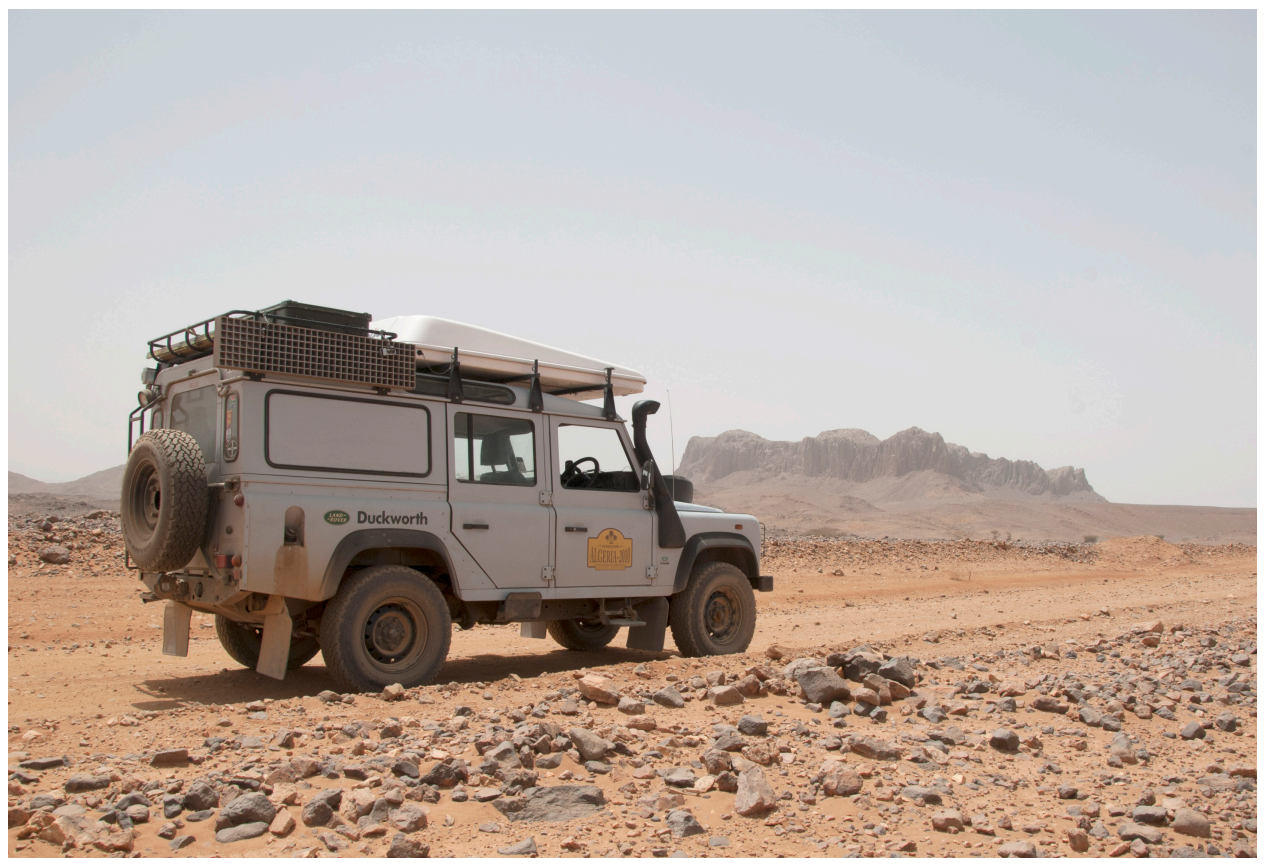

Figure 4: A Land Rover Defender on the overland trail in central Algeria, 2010. This type of experiential knowledge is essential to fully appreciate the phenomenological, social and cultural significance of this design historical artefact. Author's collection. 
However, the term 'enthusiast' carries with it connotations of the passionate amateur and by implication unstructured knowledge, subjectivity, selectivity and nostalgia. These personal interests usually form the parallel world of 'hobbies and interests' where many spend considerable time and money, and though unpaid and without obligation, often feel highly motivated and deeply engaged in a particular pastime. Are there, therefore, characteristics particular to some artefacts that mean an inanimate object can become a fascination to some, and what might this tell us about material culture as viewed through the enthusiast's eye?

The professional ethos and analytical conventions of historical scholarship can make it difficult to put aside potential prejudices about the nature of enthusiasm, but doing just that is necessary if we are to better understand the nature of enthusiasm in relation to material culture. If too ready to link the 'enthusiast' to ideas of 'celebration' or irrelevant 'niche interests' design historians are ignoring factors that can help explain the cultural resonance of some artefacts in relation to others as well as underestimate the value of archival material held in private collections that can be rich sources for design historical research.

Equally important, though, is the self-reflexive lesson to be learned: Acknowledging that one's own research, at least initially, might be driven by enthusiasm for a topic may mean we need to reappraise the word and examine its merits rather than pretend that our enthusiasms do not influence our research or that enthusiasts do not have something to offer the academic study of material culture. Enthusiasms, or the examination of other people's or group's enthusiasms, can provide an alternative starting point for research that from the outset acknowledges the complex personal relationship we have with objects. 
The assumption that all enthusiasts, collectors and amateur historians are dilettantes with no real commitment or structured knowledge means that professional historians neglect a useful resource for their research. Historians have often underestimated enthusiasts and what, sometime unwittingly, they reveal about material culture. The enthusiast can make the transparent visible by selectively highlighting examples of material culture, and as a by-product of their personal interest, encourage academics to look again at an artefact and consider its significance. Enthusiasts, or one's personal enthusiasms, can flag-up areas of potential research that design historians might at first consider unworthy of examination. As historians we are likely to discount individual eccentric collectors of the mundane such as traffic cones or tea cosies. However, if there is an observable, or even measurable, clustering of subjective personal opinions this pattern or phenomenon may be both significant and revealing if examined. It is not so much subscribing to 'the wisdom of the crowd' — an approach an academic is likely to resist—but rather being aware that a group or an enthusiastic individual may highlight an aspect of material culture previously ignored or undervalued by historians, which therefore provides a useful starting point for new research.

To give an emerging example: one might examine 3D printing and the growing communities of on-line enthusiasts who are beginning to create and share data files of virtual objects that can now be made physical using the new technology. This type of technology has the potential to significantly change our relationship with material culture in much the same way the Internet has changed our relationship with information. These enthusiast groups, though currently niche, highlight this emerging shift in our interaction with materiality in a concentrated form. The design historian 
can then look for historic parallels in the democratisation of design to better explain the emerging phenomenon and its possible consequences (Knott, 2013).

\section{Enthusiasms and Experiences}

Direct experience of, or interaction with, an artefact leads to a different and often more profound understanding of the object. It is rather a cliché but the Chinese proverb, 'What I hear I forget, what I see I remember, what I do I understand' goes some way to explaining the advantage of this direct interaction. Experimental archaeologists have long known this and regularly reconstruct historical artefacts or whole environments to better understand their use and limitations. Likewise, anthropologists will immerse themselves in an environment or culture for long periods for similar reasons. Even historians, both of technology and of design, have pointed out how the value of 'hands-on' experiential knowledge to historical scholarship has been gravely underestimated (Corn, 1996; Walker, 1989: 5). Yet design historians spend extended periods of time using the artefact they are studying far too infrequently, despite the relatively easy access to many of these items (Author, 2013b).

Interacting with the artefact is usually fundamental to the enthusiast, however. For example, for many classic and vintage car enthusiasts it is not enough to only study the vehicle and its history. They want to own it, use it and experience how the artefact feels in use. As Oddy points out, though, 'of all the approaches to objects that can be had from collector/enthusiasts, this is the most problematic for the academic to engage with on the same level because it is so personal and subjective' (Oddy, 2013). We would do well to overcome this reluctance, however, because such visceral interaction, though subjective and hard to define, can be a starting point for 
understanding the characteristics of an emotive artefact beyond the theoretical and can inform our understanding of why a design ultimately carries its particular value complexes.

This use of an historic artefact can also lead to a change in the way it is perceived. The object moves out of potential obsolescence or being perceived as a static museum piece, to become an object inhabiting the world now and our understanding or perception of it changes as a result. For instance, in interview, a senior designer at Land Rover described the Defender, with not a little irony, as: 'a classic car you can buy new!' (Crowley-Palmer, 2012). To take a much older automotive artefact, an Edwardian car, and see it used on a modern road at an event such as the annual 'London to Brighton Veteran Car Run' in the south of England, shifts ones thinking about such a vehicles place in history. The exposure of the occupants to the elements, the smile or grimace on their face depending on the weather conditions, the slowness (or sometimes surprising speed), the smell, the noise all challenge the bystanders received understanding of 'vintage'. This expanding of one's perception to embrace the subjective can also be experienced by the design historian if they interact with an artefact directly. The 'presence of the past' is all around. A fascinating example can be found in Milan, where 200 of the 500 'tipo 28' trams built in 1927-1930 are still in operation. Stepping into an 85-year-old tram in the midst of contemporary city life is an exercise in historical awareness to historians and non-historians alike - even to passengers who are not tram cognoscenti, and constitutes one of many examples of what David Edgerton has called 'the shock of the old' (Edgerton, 2006). Such enthusiastic experience may then prompt new questions and lines of investigation into material culture. 


\section{Engaging with Enthusiasts}

Viewing material culture through the enthusiast's eye may provide a new or additional perspective to the design historian. Enthusiasts can, however, be highly selective both with regard to historic periods as well as the particular artefacts with which they engage, even if their interests are diverse and the knowledge often considerable. So for example you will find individuals who enthuse about a very particular type of artefact, a specific car for example. But equally you will find enthusiasts focusing on a range of related artefacts, from valve radios to old garden implements. The borders of an enthusiast's interests may be affected by many factors: budget, availability of examples, background etc. This means the expertise individuals and enthusiast groups hold and the artefacts they enthuse about, are often a mosaic of specialist interests. These constituent pieces may contain vast amounts of detail and archival material but other pieces required to construct the over-all picture are missing altogether. The enthusiast may be unaware, or downplay, the significance of these missing pieces and wish to expand their narrative for a given artefact further than the evidence can support.

This is where and why Foucault's insistence on the union of unsanctioned and sanctioned knowledge becomes crucial. The professional historian's contextual understanding, theoretical references, methodological repertoire and source criticism is essential in guiding the focus of the enthusiast's eye, thereby sanctioning unsanctioned knowledge.

\section{Conclusion}

We are still at the early stages of examining enthusiasm in relation to material culture, and it seems there is much to investigate. There is still only a small and rather 
scattered collection of research relating to design and the enthusiast (and the word is seldom mentioned specifically). However, the recent claim that 'Historians should not shun subjectivity and personal experience, but rather investigate its methodological and historiographical potential' (Author, 2013b) allows ample space for further exploration of what the enthusiast's eye can contribute to design historical scholarship.

Increased interest in the interplay between enthusiasts and artefacts is emerging, whether it is the design historians themselves using their own areas of enthusiasm as a starting point or exploring the focuses of special interest groups. There is also an increased willingness to critically evaluate commonly used, but subjective, terms such as 'iconic', 'classic' and 'enthusiast' in an academic setting (Lees-Maffei, 2014; Olsen, 2010). Most designers are used to considering the user perspective in their work, and indeed are trained to do so. Correspondingly, historians are increasingly interested in 'how users matter' (Oudshoorn and Pinch, 2003). Therefore, if the enthusiast is a user of historic artefacts, perhaps the time is right for design historians to incorporate these forms of subjective user experiences into their analyses and grapple with the consequences as an additional means of understanding our complex relationship with material culture. 


\section{References}

Atkinson, Paul, ed. 2006. Do It Yourself: Democracy and Design. Special Issue of Journal of Design History 19(1).

Author. 2012.

Author. 2013a.

Author. 2013b.

Author. 2013c.

Author. 2014.

Beegan, Gerry, Paul Atkinson and Deborah Sugg Ryan, eds. 2008. Ghosts of the Profession: Amateur, Vernacular and Dilettante Practices and Modern Design. Special Issue of Journal of Design History 21(4).

Bell, Claudia. 2013. "Collectors as Guardians of National Artifacts." Home Cultures 10(1): 43-62.

Bijker, Wiebe E. 1997. Of Bicycles, Bakelites, and Bulbs: Toward a Theory of Sociotechnical Change. Cambridge, Mass.: MIT Press.

Bishop, Michael. 2011. They Found Our Engineer: The Story of Arthur Goddard, The Land Rover's First Engineer. Milton Keynes: AuthorHouse UK Ltd

Corn, Joseph J. 1996. “Object Lessons/Object Myths? What Historians of Technology Learn from Things.” In Learning From Things: Method and Material of Material Culture Studies, edited by W. David Kingery, 35-54.

Washington, D.C.: Smithsonian Institution Press.

Crathorne, Roger (Head of Technical Communications at Land Rover and an engineer at the company since 1964), interview with the Author, $7^{\text {th }}$ August 2009. 
Crowley-Palmer, Peter (Senior Designer at Jaguar Land Rover), interview with the Author, $3^{\text {rd }}$ January 2012.

Edgerton, David. 2006. The Shock of the Old: Technology and Global History Since 1900. London: Profile Books.

Foucault, Michel. 1980. Power/Knowledge: Selected Interviews and Other Writings 1972-1977. Colin Gordon, ed. New York: Pantheon.

Jackson, Andrew. 2010. "Constructing at Home: Understanding the Experience of the Amateur Maker", Design and Culture 2(1): 5-26.

Jackson, Andrew. 2013. "Understanding the Home Workshop: Project Space, Project Time, and Material Interaction", Interiors 4(2): 175-194.

Keyte, Julia. 2013. "Objects in Purgatory: How We Live with Uncherished Gifts”, Interiors 4(3): 315-338.

Knott, Stephen. 2013. "Design in the Age of Prosumption: The Craft of Design after the Object", Design and Culture 5(1): 45-67.

Lees-Maffei, Grace, ed. 2014. Iconic Designs: 50 Stories About 50 Objects. London: Bloomsbury Academic.

Linder, Mads, ed. 2013. Norwegian Icons: Important Norwegian Design from the Era 1940-1975. Oslo: Fuglen \& Blomqvist.

Meikle, Jeffrey L. 1998. "Material Virtues: On the Ideal and the Real in Design History." Journal of Design History 11(3): 191-199.

Morris, Jonathan. 2013. "Espresso by Design: The Creation of the Italian Coffee Machine.” In Made in Italy: Rethinking a Century of Italian Design, edited by Grace Lees-Maffei and Kjetil Fallan, 225-238. London: Bloomsbury Academic. 
Norman, Donald A. 1998. The Design of Everyday Things. Cambridge, Mass.: MIT Press.

Norman, Donald A. 2004. Emotional Design: Why We Love (or Hate) Everyday Things. New York: Basic Books.

Oddy, Nicholas. 2013. “An Uneasy Alliance: Collectors' Items and History”. Paper presented at the Design History Society Day Seminar "It's Personal: Subjectivity in Design History”, University of Hertfordshire, Hatfield, May 9.

Olsen, Bjørnar. 2010. In Defence of Things: Archaeology and the Ontology of Objects. Plymouth: AltaMira Press

Oudshoorn, Nelly and Trevor Pinch, eds. 2003. How Users Matter: The CoConstruction of Users and Technology. Cambridge, Mass.: MIT Press.

Ringdal, Siv. 2014. “110 Volts at Home: The American Lista.” Journal of Design History 27(1) [Forthcoming].]

Robson, Graham. 1976. The Land Rover: Workhorse of the World. Newton Abbot: David \& Charles (Publishers) Ltd

Sandino, Linda and Matthew Partington, eds. 2013. Oral History in the Visual Arts. London: Bloomsbury Academic.

Shove, Elizabeth, Matthew Watson, Martin Hand and Jack Ingram. 2007. The Design of Everyday Life. Oxford: Berg Publishers.

Sudjic, Deyan. 2008. The Language of Things: Design, Luxury, Fashion and Art. How We Are Seduced by the Objects Around Us. London: Penguin Books Walker, John A. 1989. Design History and the History of Design. London: Pluto Press. 